\title{
Sobre a possibilidade de escutar o Outro: voz, world music, interculturalidade
}

\section{Simone Luci Pereira}

\section{Resumo}

Partindo de uma inquietação suscitada pela leitura de um texto de Roland Barthes de 1968 - em que afirmava que a voz é o que está realmente em jogo na modernidade - este texto faz uma discussão conceitual sobre a escuta midiática na era global. Abordando também o conceito de world music, discutimos a escuta como forma de consumo cultural que pode possibilitar 0 conhecimento do Outro, do diferente, mediado pela técnica nas canções midiáticas, num momento em que fluxos globais e locais se acham em confronto e negociação, configurando espaços interculturais. Neste contexto, a voz e a escuta midiática adquirem papel de destaque num mundo em que identidades e sentidos de pertencimento se encontram em reconstrução constante. Uma escuta que põe em jogo novas articulações entre próprio/estrangeiro, local/global, em que "escutar é escutar-se" (Barthes).

\section{Palavras-chave}

Escuta. World music. Paisagem sonora. Mundialização. Interculturalidade.

Simone Luci Pereira I simonelp@uol.com.br Doutora em Antropologia pela Pontifícia Universidade Católica de São Paulo (PUC/SP). Pós-Doutoranda em Música na Universidade Federal do Estado do Rio de Janeiro (UNIRIO) - Bolsista FAPERJ (PD Sênior) e pesquisadora do Centro de Estudos em Música e Mídia (MUSIMID).

\section{Introdução}

Este texto ${ }^{1}$ apresenta uma discussão conceitual sobre a questão da escuta e da presença da voz na sociedade midiática e intercultural, em que as canções e aquilo que se nomeia comumente como world music contribuem para uma reflexão sobre 0 fenômeno da globalização no seu sentido cultural.

A origem deste texto vem de uma inquietação suscitada pela leitura de Roland Barthes que, num ensaio de 1968 chamado Lesson in writing, afirmava que a voz é o que está cada vez mais em jogo na modernidade. 0 autor sugeria que, mais do que uma civilização da imagem, no mundo moderno as atividades de lazer e de entretenimento têm como predominantes a fala e a voz, configurando-se numa civilização do discurso (speech) (BARTHES, 1984).

Avançando mais em sua argumentação, percebese que Barthes propõe uma distinção entre 
voz e língua. Esta voz estaria em risco devido à prevalência de um discurso de expressão $\mathrm{e}$ representação baseado em uma cultura assentada na comunicação linguística (verbal). 0 autor se referia à generalização cada vez maior das tecnologias da fala, tais como telefonia e transmissão de rádio e mesmo a televisão, em que predominam a voz e as palavras, constituindo 0 que se nomeia linguagem audiovisual.

Podemos interpretar que Roland Barthes busca com estas colocações aprofundar, trazer mais elementos e até se contrapor a uma certa tendência corrente nos estudos de Comunicação (mas não apenas nestes) que argumentam sobre a primazia da imagem e do visual na sociedade moderna e midiática. Uma suspeita que Barthes já parecia anunciar em seus trabalhos sobre a fotografia e a publicidade e que nos ensaios sobre a voz, a escuta e a música ficaria ainda mais nítida.

Destacamos um pouco mais as considerações de Barthes sobre a diferenciação esboçada entre língua/palavra como o componente verbal da fala e a voz, como sendo a pura expressividade do corpo. A voz como substância específica da comunicação, para além das palavras e da linguagem verbal, numa valorização dos significados corporais dos atos comunicativos, 0 que está presente em seu famoso ensaio $O$ grão da voz (BARTHES, 1990). Barthes atribui importância ao significado deste "grão da voz" presente em toda fala/canto desvinculados da palavra, procurando desvendar como ocorre a escuta da voz, tomando-a em sua especificidade, não vinculada exclusiva e necessariamente ao significado verbal. Neste caminho, formulase aquilo que Janete El Haouli (2002) chama de "voz-música", significando tudo o que a capacidade vocal está apta a produzir. Em ambos os autores, o que nos fica é a necessidade de dar atenção à presença de um corpo, a presença humana em toda vocalização, uma voz em sua expressão mais essencial e fundamental, anterior à linguagem verbal. Voltaremos a esta questão da voz e da escuta e de como ela pode possibilitar 0 conhecimento do Outro mais à frente.

Parece válido nos indagar se hoje, século XXI, esta presença da voz ainda se mostra da mesma maneira como Barthes sugeria há 40 anos. Este artigo não tem a pretensão de dar esta resposta e nem esgotar este assunto, mas apenas contribuir com algumas reflexões acerca do sonoro e do visual na sociedade global contemporânea. A característica das canções de combinar elementos que se juntam e se transformam foi intensificada com 0 advento das mídias e com a globalização/mundialização, redefinindo noções sobre identidade e fronteiras culturais, problematizando noções como tradição/ modernidade, local/global, próprio/estrangeiro, configurando territórios interculturais de confronto e negociação. Procuramos compreender o papel específico da escuta como formuladora de sentidos, de interpretações sobre 0 mundo, sobre as culturas, sobre o Outro, numa realidade em que os deslocamentos/migrações e a presença das mídias parecem cada vez mais atuar na construção e 
rearticulação das identidades, em meio aos fluxos locais/globais. Estabelecendo pontes ou caminhos de diálogo entre os campos da Comunicação e Antropologia, buscamos compreender os fenômenos ligados e engendrados pelas mídias sonoras e a escuta midiática.

Este caminho de reflexão vem se esboçando desde a elaboração de minha tese de doutorado. ${ }^{2}$ Naquela ocasião, analisei as experiências de escuta das canções da Bossa Nova no Rio de Janeiro, nos anos 1950 e 1960, por meio da interpretação das memórias de seus ouvintes na atualidade, onde questões histórico-sociais foram dialogadas com outras mais diretamente vinculadas às mídias sonoras (indústria fonográfica), escuta, tecnologias de gravação e difusão, entre outras. A vereda aberta por este trabalho tem sido uma compreensão cultural da escuta na atualidade (como algo ativo na atribuição de sentidos), da memória, das paisagens sonoras e das músicas midiáticas, num caminho de pesquisa que relaciona e tensiona os campos da Antropologia/ Comunicação/Música. A abordagem cultural do tema é um dos caminhos que a Antropologia pode oferecer ao estudo das mídias sonoras.

\section{Cultura midiática, world music, mundialização}

Não é nenhuma novidade argumentar que 0 estágio atual da modernidade capitalista é caracterizado por uma aceleração tecnológica que vem suscitando novas variáveis técnicas, econômicas, políticas e culturais interligadas, configurando aquilo que já há algum tempo vem sendo chamado de globalização. Como argumenta Renato Ortiz (1994), deve haver uma distinção entre o que chama de global e mundial, sendo o primeiro termo aplicado ao que se refere a processos tecnológicos e econômicos e 0 segundo usado para conceituar o que é do domínio específico da cultura. Estas transformações só são possíveis no seio de uma sociedade em que 0 desenvolvimento técnico acompanha o processo de globalização, ajudando a operacionalizá-la.

De acordo com Nestor García Canclini (2007a), é no âmbito da cultura que se revelam mais propriamente os variados sinais deste fenômeno que se acha em curso. Convém, segundo ele, refletir sobre que perguntas pode a interculturalidade fazer à globalização, ou seja, problematizarmos como fazer arte, cultura e comunicação nesta etapa atual, colocando em pauta os conflitos entre imaginários. 0 olhar cultural sobre a globalização evidencia um processo redefinidor das especificidades, dos regionalismos, das localidades, apontando para temas como a desterritorialização dos bens simbólicos, das ideias, das pessoas, a proliferação de colagens, hibridações, o nascimento de uma cultura mundial que, ao invés de aniquilar as outras manifestações culturais, interage e se alimenta delas. 
Nesta mesma abordagem podem ser alinhados os estudos do antropólogo Arjun Appadurai (2004), ao salientar o papel da cultura (ou "do cultural", como ele prefere) nas junções e disjunções engendradas pelos fluxos globais na contemporaneidade. De acordo com 0 autor, o "corte" com o passado verificado nos dias atuais é diferente daquele ocorrido no início dos tempos modernos (séculos XVIII e XIX). Trata-se de uma ruptura em que os meios de comunicação social e a migração assumem destaque e protagonismo, exercendo seus efeitos conjuntos sobre aquilo que Appadurai (2004) chama de a "obra da imaginação" como característica constitutiva da subjetividade moderna. Assim, a comunicação eletrônica e as migrações (que não são fenômenos novos, mas que atingiram nos últimos anos um grau de circulação nunca antes visto) ajudam a criar imaginários sociais novos que misturam, articulam e jogam em confronto fluxos culturais globais e locais, criando "esferas públicas de diáspora" em que a noção de diferença, alteridade, interculturalidade se impõem para refletirmos sobre os fenômenos culturais globais da contemporaneidade - que supõem a mistura, os paradoxos, as relações, as diferenças em confronto. (APPADURAI, 2004, p. 15)

Verifica-se, nesse sentido, a importância da cultura neste processo, a partir daí, segundo Appadurai (2004), nomeada não como substantivo (cultura), mas como adjetivo (cultural). Esta mudança no termo proposta pelo autor evidencia sua preocupação em retirar uma certa ideia de essencialidade e etnia que o termo cultura pode suscitar, assumindo 0 adjetivo cultural por ser este relacional, trazer à tona aquilo que é tão caro à Antropologia: a noção de diferença, alteridade, interculturalidade. Realmente, para se poder refletir sobre os fenômenos culturais globais da contemporaneidade - que supõem a mistura, os paradoxos, 0 relacional -0 adjetivo "cultural" parece ser mais apropriado. Lembrando ainda García Canclini (2007a, p. 12), pensar as identidades em meio à globalização significa examinar os processos culturais que nos aproximam e que nos afastam, constituindo "esferas públicas transnacionais".

Vão se esboçando aí algumas contribuições que 0 campo da Antropologia pode trazer ao estudo das dimensões globais culturais do mundo atual e o papel das mídias - em particular as sonoras - neste processo. A escuta midiática assume este papel de possibilitar o conhecimento do distante, do diferente, o que não está isento de conflitos, preconceitos, ideologias, mas que, de alguma forma, colabora neste processo de jogo e confronto de imaginários a que a globalização nos desafia. Pois as culturas regionais, locais ou populares vêm se modificando e se redefinindo no confronto com os 
processos e fluxos globais. ${ }^{3}$ Nesse sentido, é importante refletir sobre o papel das mídias na formulação, articulação e reconfiguração das identidades nacionais e culturais. Num mundo que parece dominado por repertórios culturais e imaginários coletivos globais que ainda conservam e arrastam vestígios locais - intensificando a complexidade e as contradições entre próprio/estrangeiro - os meios comunicacionais e as canções midiáticas passam a ter papel central na mediação e construção destas novas identidades híbridas, fragmentadas, múltiplas (HALL, 1997).

No que tange à música midiática, este processo tem se mostrado atuante no cerne das culturas tradicionais, as quais também têm interferido nos produtos da mídia global. Segundo Heloisa Valente, a partir dos anos 1990 verifica-se uma exacerbação de gêneros musicais já criados e a mistura destes com elementos advindos de tradições locais, transfigurando-se naquilo que vem sendo chamado de world music, onde se enquadram as manifestações musicais não pertencentes ao universo pop da cultura global, não de maneira autóctone ou preservando as características musicais originais/locais, mas sim hibridadas a elementos que lhes confiram roupagens e arranjos modernos (VALENTE, 2003a).
A discussão sobre o fato da world music se constituir num gênero específico de música é longa e complexa. Argumenta-se que o conceito ajuda a reforçar a distinção entre primeiro e terceiro mundo, ou mesmo traz uma exotização e subvalorização das culturas locais, trazendo mal-entendidos na medida em que 0 que é vendido como world music retira o conteúdo e 0 significado original de uma expressão musical (ritual, religiosa, mítica) e atribuilhe novos sentidos, roupagens e usos sociais, como entretenimento e consumo, por exemplo (BARAÑO et alli, 2003). A world music muitas vezes apresenta uma pasteurização sonora materializada em algo comumente chamado "música eletrônica", em que ritmos, harmonias, melodias são homogeneizadas de modo a que não se identifique com facilidade os traços musicais, as sonoridades específicas de uma música local, sendo tocadas em aeroportos, lounges, shopping centers, traduzindo-se em um "não-som" (em alusão ao conceito de "não-lugar", de Marc Augé), um som sem traços específicos, particulares, locais. Configura-se, assim, uma ideia de "músicas invisíveis" (MARTÍ, 2004), aquelas que se ouvem sem necessidade de serem escutadas, presentes no cotidiano (filmes, publicidade, supermercados, salas de espera), passando na maioria das vezes desapercebidos.

Impossível dissociar o crescente avanço da globalização e a redefinição das culturas locais, uma vez que no próprio interior da globalização midiática já se esboçam as suas contradições. Se for verdade que, do ponto de vista econômico, os sistemas de comunicação se globalizaram, formando grandes conglomerados de empresas que combinam controle do rádio, televisão, imprensa, indústria fonográfica, também é necessário considerar que as mensagens que são aí produzidas apontam para características de especialização, localismos e multiplicidade e não apenas de homogeneização e massificação como tantas vezes se argumenta (MIRA, 1994). 
Hoje em dia, ocorre na música midiática um renovado gosto pelas raízes, pela retomada de elementos das culturas regionais, tradicionais, folclóricas para misturá-las com tecnologias mais recentes, o que se mostra como uma estratégia das indústrias fonográficas na busca pela segmentação do mercado e adequação aos diferentes grupos de consumo. Se tomarmos o campo da música eletrônica, por exemplo, verificamos que 0 gosto por elementos exóticos, diferentes (inclusive com instrumentos de percussão executados ao vivo, ao lado dos DJs) mesclados a sonoridades outras já vem adquirindo um sinal de "distinção" (BOURDIEU, 1988) na luta incessante por hegemonia, denotando um caráter de bom gosto, sofisticação, vanguarda, frente a outras manifestações da mesma música que não produzem essas fusões. De fato, o conceito de world music, aparentemente exaltando e cantando a diversidade, não deixa de enquadrar esta diversidade dentro de estruturas de hierarquia social e padrões de gosto e legitimação cultural.

Assim, pensar os movimentos culturais em meio ao mundo global, significa assumir que as necessidades inerentes ao campo (BOURDIEU, 1988) musical neste momento mostram-se atuantes, materializadas na necessidade por renovação, pelo alternativo, exótico, o diferente. Um campo musical em que identidades fragmentadas, locais e vozes, sons e performances em movimento, misturadas, "mixadas", com capacidade de se integrarem a identidades múltiplas detêm valor e legitimidade no mercado de bens simbólicos.

Entretanto, mesmo tendo consciência deste processo mercadológico e ideológico atual de busca por legitimidades, hegemonia, poder, que envolve a música e a cultura, não esquecemos 0 fato de que as paisagens sonoras (conceito que será discutido mais à frente) e a escuta midiática estejam também apontando para a formação de identidades múltiplas, fruto da diáspora global da cultura, das sensibilidades dos modos de escutar o mundo, gerando gostos musicais, escutas e pertencimentos que fogem ao esquemático padrão das legitimidades (ortodoxas e heterodoxas) do campo cultural/musical. Um consumo cultural musical que pode ter um sentido político, agregador, articulando novas identidades, novos pertencimentos e novas redes simbólicas, formulando novas "esferas públicas de diáspora" (APPADURAI, 2004).

Não se supõe aqui, portanto, uma aniquilação das músicas tradicionais/locais, mas a elaboração de um repertório compartilhado de sons, ritmos, melodias, vozes e, particularmente, de uma escuta global/mundial que se acha em cristalização neste momento, que se faz e refaz a partir do confronto e negociação entre fluxos globais e locais. Um ouvinte da atualidade que tem a possibilidade de escutar ou obter (via download, streaming, redes de compartilhamento) quase todas as músicas do mundo que se encontram ao seu alcance, formulando uma escuta própria a este 
tempo. Um processo global que permeia o conjunto das manifestações culturais, se localizando, enraizando nas práticas cotidianas dos indivíduos. Importa conhecer, neste sentido, como esta ligação e confronto entre local/nacional/global vem atuando na produção de localidades (APPADURAI, 2004), ou seja, na forma como estas culturas locais vem se configurando, reconstruindo, esboçando novas identidades, novos pertencimentos.

A escuta contemporânea vem se mostrando como um campo aberto para a reflexão sobre a forma como 0 ambiente urbano, a imaginação global, as novas tecnologias incidem nos afetos e percepções dos ouvintes. Se gêneros musicais como fado, samba, bossa nova, bolero, tango apresentam cada vez mais combinações de elementos que se fundem, misturam e se transformam (forçando uma redefinição da ideia de gêneros atrelados às identidades nacionais), os modos de escuta em meio a mundialização também vão se modificando, seja nos modos de lidar com as técnicas e suportes do universo sônico, seja nas formas de apreciação e formulação dos gostos musicais, afetados e modificados pela paisagem sonora e as tecnologias presentes nas gravações. Redefinem-se noções sobre fronteiras entre identidades musicais, culturais e nacionais estabelecidas. A análise da música em sua performance (ZUMTHOR, 1997) técnicas vocais e gestuais, usos das tecnologias de gravação, arranjos, reverberação ajuda a compreender paisagens sonoras em mudança, onde a escuta, para além de ser musical, é entendida como uma escuta do mundo.
Assim, se 0 problema central das interações globais parece ser a tensão entre homogeneização e heterogeneização cultural, é preciso assumir que esta tensão não é simples, nem dicotômica, mas sim complexa, disjuntiva, em que já não se podem compreender os fenômenos pelos termos centro/ periferia ou consumidores/produtores. Retomando os argumentos de Appadurai (2004, p. 50), a "economia cultural global" de hoje tem a ver com disjunturas e paradoxos que 0 autor tenta explorar a partir de cinco dimensões de fluxos culturais globais. Um primeiro, etnopaisagem, designaria a paisagem de pessoas que constituem o mundo em deslocamento - turistas, imigrantes, refugiados, trabalhadores convidados. - que ajudam a conformar novos imaginários sociais sobre locais, países, culturas. 0 segundo, tecnopaisagem, refere-se a configuração global cada vez mais fluida da tecnologia transpondo fronteiras antes impenetráveis. 0 terceiro, financiopaisagem, muito articulado a tecnopaisagem, evidencia 0 quanto o capital global mostra-se rápido, difícil de seguir, imprevisível. Um quarto elemento seria a mediapaisagem, que designa a capacidade eletrônica para produzir e disseminar informações (impressas, eletrônicas, sonoras, imagéticas) que ficam ao dispor de um número crescente de pessoas, trazendo representações e imagens de mundos, países, locais diferentes, ajudando a elaborar imaginários sociais cada vez mais complexos e globais, fornecendo ainda vastos e complexos repertórios de imagens, narrativas, sons, vozes ao mundo todo, construindo "pedaços de realidade" e formas de conhecimento do 
Outro, do diferente, do longínquo. Por fim, 0 quinto elemento é a ideopaisagem, que são também imagens, narrativas e ideias espalhadas eletronicamente, mas que tem em geral uma conotação política e ideológica.

\section{Sonoridades, escutas e interculturalidade}

Embora Appadurai não se detenha numa reflexão sobre as mídias sonoras ou a escuta, suas ideias nos fazem pensar sobre universo sonoro e as questões vividas por este em meio a esta era global. Instigados pela ideia das paisagens apontadas por este autor, podemos pensar na noção de "paisagem sonora" (SCHAFER, 1991) e na sua estruturação, que encontra-se em mudança na contemporaneidade. Sem prolongar demais a definição e discussão sobre paisagem sonora já realizada em outro artigo (PEREIRA, 2009)

- apontamos apenas que a escuta deve ser percebida não apenas como a escuta musical, mas inserida num complexo maior que incorpora os sons das cidades, os ruídos, o meio ambiente, afetando e alterando inclusive os modos de se fazer musica e, mais ainda, as novas formas de sensibilidade audíveis, novos hábitos de escuta e de formulação de gostos musicais, aquilo que consideramos sons desejáveis e indesejáveis. Aî é que se encontra a necessidade de atentarmos "para quais efeitos têm os sons do ambiente, ou quais relações se estabelecem entre eles e a música de uma época, que diferenciações existiriam numa musicalidade composta num meio urbano, ou no campo, ou à beira mar." (PEREIRA, 2009, p. 141).

Há que se pensar na performance da canção gravada em disco como paisagem sonora. Cumpre saber que sons estão presentes, o que evocam, que sentidos lhe atribuem os ouvintes. No caso específico das canções, sons que se compõem da voz do cantor, dos instrumentos, mas também dos arranjos, das tecnologias utilizadas nas gravações, as técnicas de captação sonora, de gravação, de mixagem etc. Entra aqui o que François Delalande (2001) chama de "som", um conceito que se refere ao resultado sonoro que se obtém numa gravação, dependente de fatores técnicos, mas que é apreciado em termos estéticos, referindo-se à qualidade sonora (lo-fi ou $h i-f i)$, índice de reverberação, controle dos canais, equalização.

Pensando no som e em sua produção, podemos refletir sobre a incorporação das tecnologias na música atual até 0 limite de muitas das canções gravadas hoje, possuírem pelo menos alguns trechos de música eletroacústica, denotando uma paisagem sonora que incorpora os sons, os ruídos da modernidade, da aceleração do tempo, fazendo com que a linguagem musical se deixe permear pelos sons da cidade, das máquinas e do mundo. Uma presença cada vez maior, dentro da música, das tecnologias afetando os hábitos perceptivos, as formas de escuta, o que se entende por som de qualidade e o próprio fazer musical (CHANAN, 
2000). Isso configura um tempo em que gêneros ou estilos musicais como fado, bolero, tango, bossa nova parecem ser apreciados por muitos somente se puderem ser relidos, reelaborados, mixados com outros sons, ritmos, vozes, intensidades e timbres tal qual se fabrica no estúdio. ${ }^{4}$

As tecnologias, entretanto, não são apenas transmissoras de sons e imagens, mas também colaboram na construção de novos modos de escutar, olhar, sentir e conhecer o Outro, alterando as sensibilidades, modos de percepção e formas de conhecer e escutar o mundo e a vida. A escuta é algo entendido como uma complexa operação mental e subjetiva, corporificando a forma como os sons são recebidos pelos órgãos sensoriais, proporcionando uma escuta geradora de sentidos. Retomemos as considerações de Roland Barthes (1990), com o objetivo de compreender como escutamos os sons, como eles nos interpelam, como nos fazem sentido. 0 autor faz uma valiosa reflexão acerca da escuta, distinguido-a do ato fisiológico e mecânico de "ouvir", conferindo-lhe um estatuto de ato psicológico que só se define por seu objeto e por sua intenção. Barthes elencou ainda três tipos de escuta.

A primeira, cuja atenção é dirigida para "índices", serve de alerta à presença de alguém, de um perigo ou do objeto amado. Opera também com um princípio de seleção, avaliação e apropriação da situação espaço-temporal, captando graus de distanciamento e proximidade do mundo em volta, fazendo com que se possa distinguir o que era confuso e indeterminado, transformando-o em algo pertinente e distinto, garantindo, assim, uma certa segurança, uma vez que ajuda a definir o espaço territorial, o que é familiar e o que é estranho.

A segunda escuta refere-se à decifração. 0corre quando o ouvido busca captar signos mediante determinados códigos e a escuta se afasta da mera função vigilante para se tornar criação. Com 0 ritmo - a pulsação regular de incisões rítmicas longamente repetidas, uma característica humana que remonta ao período pré-histórico - vai se tornando possível a existência da linguagem, pois o signo está baseado entre um ir e vir do marcado e do não marcado, aquilo que Barthes chama de paradigma. A transformação do índice em signo é a característica básica da segunda escuta, que é a do sentido, da decifração não do possível (como uma presa ou o objeto de desejo), mas daquilo que está escondido, imerso na realidade - o mistério, o obscuro que espera por nossa decodificação a partir de códigos para vir à consciência. Uma escuta que acaba colocando em relação dois sujeitos, uma interpelação total de um indivíduo a outro, como um cantor que com sua voz entra em contato quase físico com 0 ouvido do sujeito que 0 ouve, em que escutar quer dizer também tocar, saber da existência do outro. Esta escuta 
decifradora transforma o homem em ser dual, numa interlocução na qual o silêncio do ouvinte é tão ativo quanto a palavra do emissor, onde a "escuta fala".

Por fim, a terceira escuta, para a qual Barthes dá uma abordagem moderna - comparando-a com a escuta psicanalítica - onde 0 que interessa é menos o dito ou o emitido, e muito mais quem fala e emite, não esperando signos determinados ou classificados, desenvolvendo um espaço intersubjetivo não concebível sem a intervenção do inconsciente estruturado como linguagem. A escuta da voz inaugura a relação com 0 outro, processo em que o movimento corporal tem muita importância. Pela voz, conhecemos a maneira de ser do outro, seu estado de alegria ou tristeza, transmitindo por vezes apenas a imagem do corpo. Aqui a voz pode, muitas vezes, encantar mais do que o próprio conteúdo do discurso.

Esta terceira escuta nos inspira a refletir sobre a escuta na era global, uma escuta do Outro, que pode ser o longínquo, o exótico, o desconhecido, mas que se faz pela midiatização e pelo trânsito de pessoas e imaginários globais pelo mundo (de forma real ou virtual). Uma realidade que ajuda a criar novas representações sociais do diferente, das outras culturas, misturando, articulando e fazendo negociar fluxos culturais globais e locais, configurando espaços públicos transnacionais em que a noção de alteridade e interculturalidade se impõem para refletirmos sobre os fenômenos culturais globais da contemporaneidade - que supõem a mistura, os paradoxos, as relações, as diferenças em confronto. Um reconhecimento do diferente que se faz em grande parte por via da escuta de canções midiáticas, em que próximo e distante se transformam em categorias fluidas, numa interação provocada pela escuta corporal, relacional, e em que a voz assume papel protagonista, quase que independente das palavras (que muitas vezes não se compreende). Identidade, alteridade, pertencimento vão se colocando de maneira complexa, num jogo de transferências, em que escutar é escutar-se (BARTHES, 1990).

0 que se impõe nesta escuta é menos aquilo que é dito, varrendo espaços desconhecidos, mas o implícito, indireto, disperso numa abertura polissêmica, desfazendo a lei de uma escuta única e entrando no âmbito do que Barthes chama de "significância". Nesta escuta total, inusitada, criativa, há um processo de fruição permitindo que 0 indivíduo conheça melhor o outro e, fundamentalmente a si próprio; numa escuta do não decifrado, do desejo, da vida.

Aprofundemos a noção barthesiana de "grão da voz" (1990), o local onde uma língua encontra uma voz, assumindo uma postura dupla: a de ser língua e a de ser música. Ele se refere àquele valor outorgado por quem escuta sobre uma voz atrelada a um corpo, numa relação "erótica" em que timbre e linguagem interagem, em que é possível 0 ouvinte dizer se gosta ou não de uma voz. Quando esta voz é agradável ao ouvinte, revela-se um 
lado abstrato prazeroso, em que a voz do cantor é individual, fazendo com que se ouça um corpo que, desconhecido seu nome, personalidade ou as palavras que entoa e mesmo sendo um corpo destituído de materialidade, transporta para a simbologia expressiva da materialidade de um corpo falando, na "volúpia de sons-significantes", fazendo brotar 0 gozo que chega até 0 ouvinte.

Sons e vozes que nos chegam de outros lugares, tempos e culturas, mas que estabelecem, no momento da escuta, a aproximação possível, um tocar e interagir pela escuta da voz e do corpo, onde "a voz brilha, pois o ouvinte nela se introjeta" (VALENTE, 2003b), estabelecendo vínculos comunicativos sentidos como aproximação tátil e envolvente. Um corpo que nos fala a partir da voz e sua dicção e materialidade, encontradas nas pronúncias, nos jeitos de expressar palavras, consoantes, vogais; mais do que a poesia e suas palavras significantes existe uma "volúpia dos sons", do "grão da voz", em que a percepção do corpo que canta traz uma escuta daquele que fala, apoderando-se dos sons e transferindo-os de volta ao emissor ("escutar é escutar-se"), numa transferência que estabelece a simbiose intérprete-ouvinte.

Ainda sobre a voz e o canto, Barthes faz uma importante distinção (baseado nas proposições de Julia Kristeva) entre feno-canção (phenosong) e geno-canção (geno-song). A feno-canção refere-se a todos os elementos que pertencem à estrutura da linguagem a ser cantada, tudo o que é colocado a serviço da comunicação, expressão e representação; feno-canção diz respeito ao plano do enunciado concreto, o discurso manifesto na música. Já a geno-canção traz a noção de germinação dos "sons-significantes", englobando todos os jogos subjacentes a essa estrutura aparente, onde melodia, uso da voz, vocalizações estão independentes das palavras e têm vida própria; a geno-canção se refere ao timbre da voz, a diçção da linguagem aparecendo não tanto pela técnica vocal ou a dramaticidade nela contida, mas pelo "grão da voz", numa articulação do corpo (voz) e da língua. Barthes deixa transparecer uma clara valorização da geno-canção, dizendo que a história e a sociologia da música (tal qual conhecemos hoje, que é puramente feno-textual) precisariam ser recontadas a partir desta nova noção, que aponta para um significante infinito (dado ao ouvinte) e não se fixa apenas nas estruturas musicais e comunicacionais. Segundo o autor, estaríamos nos afastando das potencialidades criadoras e amorosas da voz, dos seus significados para 0 humano e para a vida.

\section{Considerações Finais}

a voz transcende as culturas. Ela tem o poder de redescobrir memórias, sensações e sentimentos para os quais não temos mais palavras para traduzir ou que foram esquecidas, reprimidas [...] uma espécie de arqueologia da voz, com suas texturas, suas energias [...] a voz é uma linguagem universal. (MONK apud EL HAOULI, 2002, p. 101).

Ora, se assumimos que a escuta não é um ato passivo, é importante compreender 
as maneiras como ela se dá, quais são os elementos de identificação entre ouvinte e emissor, de que maneira escutamos canções, performances, vozes, timbres mediatizados que nos chegam de longe, de outras culturas, com as facilidades introduzidas a partir da globalização/mundialização, em que parece termos ao nosso alcance um repertório infinito de sons, vozes, paisagens sonoras - uma "discoteca" infinita. Refletir sobre a paisagem sonora, os elementos que estão presentes na performance da música midiática mostra-se como um fecundo caminho para se compreender aspectos da cultura mundializada, permeada por elementos tecnológicos, globais e também locais, referenciais. Mas, pensar no receptor, na sua escuta ativa e formuladora de sentidos, mostrase também fundamental para compreender esta mesma cultura mundializada, em que a percepção do ouvinte também se acha em transformação, integrando valores, concepções, padrões de escuta diferentes, compondo identidades culturais nômades, híbridas.

Se concordamos com Appadurai, podemos concluir que na atualidade há uma certa "esfera pública de diáspora" (APPADURAI, 2004), que vai sendo formada pelos fluxos de pessoas pelo mundo, concomitantemente às paisagens sonoras em constante mudança, bem como às sensibilidades auditivas cada vez mais transformadas em meio aos fluxos globais, onde novos arranjos identitários, de consumo cultural musical e de escuta vão se esboçando. As mídias sonoras e seus suportes (LP, CD, MP3, WMA, entre outros) são valiosos instrumentos de pesquisa e reflexão e também guardadores de performances já passadas, de outros tempos e de outros lugares. Sons e vozes que não se encontram cristalizados, mas moventes, vivos, nômades, oferecendo ao ouvinte, novos e indeterminados sentidos a cada nova escuta, em tempos e lugares diversos. A percepção que o ouvinte tem de uma canção, de uma voz, de um som, não será o mesmo feito em locais e épocas diferentes, pois a realidade e o contexto são outros, a etnopaisagem, mediapaisagem e a paisagem sonora também. ${ }^{5}$

A world music, a escuta midiática e retomando os argumentos de Barthes apontados no início deste texto a presença da voz na atualidade parecem ser um locus de análise privilegiado para se compreender os caminhos, contradições e complexidades daquilo que parece não ser apenas um conceito, mas uma realidade bastante concreta na atualidade: a

No meu estudo feito sobre a Bossa Nova (PEREIRA, 2004), foi possível perceber este processo na escuta das canções em tempo/espaços diferentes do "original" (anos 1950/60). As performances atuais se adaptam, se reintegram e se modificam num tipo de miscigenação saturada de elementos que, escutados no presente, suscitam diversas formas de percepção. Um exemplo disso pode ser a obra de Bebel Gilberto, do grupo Bossa Cuca Nova, entre outros, e mesmo a canção "Só tinha de ser com você", de Tom Jobim, quem em 2001 foi gravada e exaustivamente tocada numa roupagem "moderna", eletrônica, mixada pelo DJ Patife, incorporando drum'bass, e cantada por Fernanda Porto. Ao que tudo indica, esta é a forma audível e possível da Bossa nova para 0 grande público - e principalmente para os mais jovens - num momento em que a calma, o tempo mais lento, sugeridos pelo estilo "original" não parecem encontrar lugar num mundo acelerado e numa paisagem sonora tão diferente. 
interculturalidade (GARCÍA CANCLINI, 2007b), os espaços de encontro, confronto, negociação das culturas.

Esboçamos aqui um breve panorama a respeito de como a abordagem cultural pode contribuir na compreensão da música midiática e das escutas contemporâneas. Um caminho de reflexão que valoriza os processos de negociação entre 0 próprio e o estrangeiro, o local e o global, popular e massivo, e na reelaboração das expressões musicais e culturais para que se mantenham vivas e presentes, em meio às diásporas culturais pelo mundo que vem configurando paisagens humanas, midiáticas, sonoras transformadas e modificadas, mas cada vez mais pulsantes.

\section{Referências}

APPADURAI, Arjun. Dimensões culturais da globalização. Lisboa: Teorema, 2004.

BARAÑO, Ascención et alli. World Musici El folklore de la globalización? Revista Transcultural de Música

- Transcultural Music Review. n. 7, 2003. Disponível em: <http://www.sibetrans.com/trans/trans7/redonda. htm> Acesso em: 04 jun. 2009.

BARTHES, Roland. 0 óbvio e o obtuso: ensaios críticos III. Rio de Janeiro: Nova Fronteira, 1990. . Image, Music, Text. London: Fontana, 1984. BOURDIEU, Pierre. La distinción: criterio y bases sociales del gusto. Madri: Taurus, 1988.

CHANAN, Michael. Repeated takes: a short history of recording and its effects on music. 2.ed. London: Verso, 2000.

CHION, Michel . Musiques: médias et technologies. Paris: Flammarion, 1994.
DELALANDE, Fronçois. Le son des musiques - entre technologie et esthétique. Paris: Buchet/Chastel, 2001.

\section{GARCÍA CANCLINI, Nestor. A globalização}

imaginada. São Paulo: Iluminuras, 2007a.

.Diferentes, desiguais, desconectados:

mapas da intercultulturalidade. Rio de Janeiro: Ed.

UFRJ, 2007b.

EL HAOULI, Janete. Demetrio Stratos: em busca da voz-música. Londrina: J.E. Haouli, 2002.

HALL, Stuart. Da Diáspora: identidades e mediações culturais. Belo Horizonte: Ed. UFMG, 2003.

Identidades culturais na pós-modernidade. Rio de Janeiro: DP\&A, 1997.

MARTÍ, Josep. Transculturación, globalización y músicas de hoy. Revista Transcultural de Música Transcultural Music Review. n. 8, 2004. Disponível em: < http://www.sibetrans.com/trans/trans8/marti. htm> Acesso em: 05 jun. 2009.

MIRA, Maria Celeste. 0 global e o local: mídia, identidades e usos da cultura. Margem, São Paulo,, n. 3, p. 131-150, 1994.

ORTIZ, Renato. Mundialização e cultura. São Paulo: Brasiliense, 1994.

PEREIRA, Simone Luci. Escutas da memória: os ouvintes das canções da Bossa Nova (Rio de Janeiro, décadas de 1950 e 1960). Tese (Doutorado em Ciências Sociais - Antropologia) - PUC/SP, 2004.

Paisagens sonoras urbanas: uma contribuição ao estudo da escuta midiática. In: BORELLI, Silvia; FREITAS, Ricardo (Org.). Comunicação, narrativas e culturas urbanas. São Paulo: EDUC, 2009.

SANTOS, Fátima Carneiro. Por uma escuta nômade: a música dos sons da rua. São Paulo: Educ: FAPESP, 2002.

SCHAFER, R. Murray. 0 ouvido pensante. São Paulo: UNESP, 1991. 
. A afinação do mundo. São Paulo: UNESP,

2001.

VALENTE, Heloisa. 'Estranha forma de vida...': da popização do cult a concertização do pop. Revista GHREBH, São Paulo, n. 3, 2003a. Disponível em $<$ http://www.revista.cisc.org.br/ghrebh1/artigos. html >. Acesso em: 10 abr. 2005.

. As vozes da canção na mídia. São Paulo: Via Lettera, 2003b.

ZUMTHOR, Paul. Introdução à poesia oral. São Paulo: Hucitec, 1997. 


\section{About the possibility to listen to the Other: voice, world music, interculturality}

\section{Abstract}

Starting from a concern raised by the reading of a text of Roland Barthes, 1968 - which stated that the voice is what is really at stake in modernity - this text develops a conceptual discussion about the media listening in the global era. Also addressing the concept of world music, we discuss listening as a form of cultural consumption that can enable the knowledge of the Other, the different, mediated by technical media in the songs, at a time when global and local flows are in a confrontation and negotiation, setting intercultural spaces. In this context, the voice and listening to media acquire a prominent role in a world where identities and senses of belonging are under constant reconstruction. One hears that brings into play new connections between own / foreign, local / global, in that "listening is listening to" (Barthes).

\section{Keywords}

Listening. World music. Soundscape. Globalization. Interculturality.

\section{Sobre la possibilidad de escuchar al Otro: voz, world music, interculturalidad}

\section{Resúmen}

A partir de una inquietud suscitada por la lectura de un texto de Roland Barthes, 1968 - que establece que la voz es lo que está verdaderamente en juego en la modernidad - este texto es una discusión conceptual sobre la escucha midiatica en la era global. Abordando también el concepto de world music, debatemos la escucha como una forma de consumo cultural que puede permitir el conocimiento del otro, de la alteridad, mediado por las técnicas presentes en las canciones, en un momento en que los flujos globales y locales se encuentran en confrontación y negociación, estabeciendo espacios interculturales. En este contexto, la voz y la escucha midiática adquieren un papel destacado en un mundo donde las identidades y sentidos de pertenencia están en constante reconstrucción. Una escucha que pone en juego nuevas conexiones entre propio y extranjero, local y global, donde "escuchar significa escucharse a si mismo" (Barthes).

\section{Palabras Clave}

Escucha. World music. Paisaje sonoro. Mundialización. Interculturalidad. 


\section{Expediente}

A revista E-Compós é a publicação científica em formato eletrônico da Associação Nacional dos Programas de Pós-Graduação em Comunicação (Compós). Lançada em 2004, tem como principal finalidade difundir a produção acadêmica de pesquisadores da área de Comunicação, inseridos em instituições do Brasil e do exterior.

\section{E-COMPÓS I www.e-compos.org.br I E-ISSN 1808-2599}

Revista da Associação Nacional dos Programas

de Pós-Graduação em Comunicação.

Brasília, v.15, n.2, maio/ago. 2012.

A identificação das edições, a partir de 2008 ,

passa a ser volume anual com três números.

\section{CONSELHO EDITORIAL}

Afonso Albuquerque, Universidade Federal Fluminense, Brasil Alberto Carlos Augusto Klein, Universidade Estadual de Londrina, Brasil Álvaro Larangeira, Universidade Tuiuti do Paraná, Brasi André Luiz Martins Lemos, Universidade Federal da Bahia, Brasil Ângela Freire Prysthon, Universidade Federal de Pernambuco, Brasil Angela Cristina Salgueiro Marques, Faculdade Cásper Líbero (São Paulo), Brasil Antonio Roberto Chiachiri Filho, Faculdade Cásper Líbero, Brasil Arthur Autran Franco de Sá Neto, Universidade Federal de São Carlos, Brasil Benjamim Picado, Universidade Federal Fluminense, Brasil César Geraldo Guimarães, Universidade Federal de Minas Gerais, Brasil Cristiane Freitas Gutfreind, Pontifícia Universidade Católica do Rio Grande do Sul, Brasil

Denilson Lopes, Universidade Federal do Rio de Janeiro, Brasil Eduardo Peñuela Cañizal, Universidade Paulista, Brasi Eduardo Vicente, Universidade de São Paulo, Brasil Eneus Trindade, Universidade de São Paulo, Brasil Florence Dravet, Universidade Católica de Brasília, Brasil Gelson Santana, Universidade Anhembi/Morumbi, Brasil Gislene da Silva, Universidade Federal de Santa Catarina, Brasil Guillermo Orozco Gómez, Universidad de Guadalajara Gustavo Daudt Fischer, Universidade do Vale do Rio dos Sinos, Brasil Hector Ospina, Universidad de Manizales, Colômbia Herom Vargas, Universidade Municipal de São Caetano do Sul, Brasil Inês Vitorino, Universidade Federal do Ceará, Brasil Jay David Bolter, Georgia Institute of Technology Jeder Silveira Janotti Junior, Universidade Federal de Pernambuco, Brasil John DH Downing, University of Texas at Austin, Estados Unidos José Afonso da Silva Junior, Universidade Federal de Pernambuco, Brasil José Carlos Rodrigues, Pontifícia Universidade Católica do Rio de Janeiro, Brasi José Luiz Aidar Prado, Pontifícia Universidade Católica de São Paulo, Brasil Kelly Cristina de Souza Prudêncio, Universidade Federal do Paraná, Brasil. Laan Mendes Barros, Universidade Metodista de São Paulo, Brasil
Lance Strate, Fordham University, USA, Estados Unidos

Lorraine Leu, University of Bristol, Grã-Bretanha

Lucia Leão, Pontifícia Universidade Católica de São Paulo, Brasil

Malena Segura Contrera, Universidade Paulista, Brasil

Márcio de Vasconcellos Serelle, Pontifícia Universidade Católica de Minas Gerais, Brasil

Maria Aparecida Baccega, Universidade de São Paulo e Escola Superior de Propaganda e Marketing, Brasil

Maria Ataide Malcher, Universidade Federal do Pará, Brasi

Maria das Graças Pinto Coelho, Universidade Federal do Rio Grande do Norte, Brasil

Maria Immacolata Vassallo de Lopes, Universidade de São Paulo, Brasil Maria Luiza Martins de Mendonça, Universidade Federal de Goiás, Brasi Mauro de Souza Ventura, Universidade Estadual Paulista, Brasil Mauro Pereira Porto, Tulane University, Estados Unidos Mirna Feitoza Pereira, Universidade Federal do Amazonas, Brasil Nilda Aparecida Jacks, Universidade Federal do Rio Grande do Sul, Brasil Osvando J. de Morais, Universidade de Sorocaba, Brasil Potiguara Mendes Silveira Jr, Universidade Federal de Juiz de Fora, Brasil Renato Cordeiro Gomes, Pontifícia Universidade Católica do Rio de Janeiro, Brasil Robert K Logan, University of Toronto, Canadá

Ronaldo George Helal, Universidade do Estado do Rio de Janeiro, Brasil Rose Melo Rocha, Escola Superior de Propaganda e Marketing, Brasil Rossana Reguillo, Instituto de Estudos Superiores do Ocidente, Mexico Rousiley Celi Moreira Maia, Universidade Federal de Minas Gerais, Brasil Sebastião Guilherme Albano da Costa, Universidade Federal do Rio Grande do Norte, Brasil

Simone Maria Andrade Pereira de Sá, Universidade Federal Fluminense, Brasil Tiago Quiroga Fausto Neto, Universidade de Brasília, Brasil Suzete Venturelli, Universidade de Brasília, Brasil Valerio Fuenzalida Fernández, Puc-Chile, Chile Veneza Mayora Ronsini, Universidade Federal de Santa Maria, Brasil Vera Regina Veiga França, Universidade Federal de Minas Gerais, Brasil

\section{COMISSÃO EDITORIAL}

Adriana Braga I Pontifícia Universidade Católica do Rio de Janeiro, Brasil

Felipe Costa Trotta I Universidade Federal Fluminense, Brasi

CONSULTORES AD HOC

Adriana Amaral, Universidade do Vale do Rio dos Sinos, Brasil

Ana Carolina Escosteguy, Pontifícia Universidade Católica do Rio Grande do Sul, Brasi Claudia Azevedo, Universidade Federal do Estado do Rio de Janeiro, Brasil Gisela Castro, Escola Superior de Propaganda e Marketing, Brasil Luis Queiroz, Universidade Federal da Paraíba, Brasil Rodrigo Carreiro, Universidade Federal de Pernambuco, Brasil EDIÇÃO DE TEXTO E RESUMOS I Susane Barros SECRETÁRIA EXECUTIVA I Juliana Depiné EDITORAÇÃO ELETRÔNICA I Roka Estúdio TRADUÇÃo I Sieni Campos
COMPÓS I www.compos.org.br

Associação Nacional dos Programas de Pós-Graduação em Comunicação

Presidente

Julio Pinto

Pontifícia Universidade Católica de Minas Gerais, Brasil juliopinto@pucminas.br

Vice-presidente

Itania Maria Mota Gomes

Universidade Federal da Bahia, Brasil

itania@ufba.br

Secretária-Geral

Inês Vitorino

Universidade Federal do Ceará, Brasil

inesvic@gmail.com 